\title{
Symbiosis dependent accumulation of primary metabolites in arbuscule-containing cells
}

\author{
Nicole Gaude*, Silvia Bortfeld, Alexander Erban, Joachim Kopka and Franziska Krajinski
}

\begin{abstract}
Background: The arbuscular mycorrhizal symbiosis is characterized by the presence of different symbiotic structures and stages within a root system. Therefore tools allowing the analysis of molecular changes at a cellular level are required to reveal insight into arbuscular mycorrhizal (AM) symbiosis development and functioning.

Results: Here we describe the analysis of metabolite pools in arbuscule-containing cells, which are the site of nutrient transfer between AM fungus and host plant. Laser capture microdissection (LCM) combined with gas chromatography mass spectrometry (GC-EI/TOF-MS) enabled the analysis of primary metabolite levels,which might be of plant or fungal origin, within these cells.

Conclusions: High levels of the amino acids, aspartate, asparagine, glutamate, and glutamine, were observed in arbuscule-containing cells. Elevated amounts of sucrose and the steady-state of hexose levels indicated a direct assimilation of monosaccharides by the fungal partner.
\end{abstract}

\section{Background}

The arbuscular mycorrhiza symbiosis (AM symbiosis) is a widespread mutualistic association. AM symbiosis involves a mutually beneficial nutrient exchange at symbiotic interfaces, in particular, phosphate and nitrogen translocation to the plant. On the other hand carbon is supplied mainly in the form of carbohydrates to the biotrophic AM fungus. During the symbiotic interaction, both partners undergo significant morphological and physiological modifications which involve alterations of the metabolite profile [1-4]. It is known that extraradical fungal hyphae take up different forms of nitrogen from the soil and transfer it to the host plant [5-8]. In addition, root carbohydrate pools are substantially altered in mycorrhizal plants $[9,10]$.

The AM symbiosis is characterized by the formation of highly branched structures within host cells, the arbuscules. Arbuscules are formed in the inner root cortex of mycorrhizal roots. These intracellular structures are the major site of a reciprocal nutrient transfer facilitated by a number of transporters located in the periarbuscular membrane (PAM) surrounding the arbuscules

\footnotetext{
* Correspondence: Gaude@mpimp-golm.mpg.de

Max Planck Institute of Molecular Plant Physiology, Am Muehlenberg 1,

14476 Potsdam, Germany
}

[11]. The development of the arbuscules is an asynchronous process. The distribution of all developmental stages in the root and a continual re-colonization of cortex cells complicate the analysis of specific reprogramming processes at the level of the whole root organ.

Therefore the application of single-cell isolation methods, i.e., laser microdissection, is required to analyse the celllif accumulation of specialized small molecules such or become detectable only at specific developmental of the plant-fungus interaction. Laser microdissecwas already successfully employed to investigate cellplants [13-21].

GC-MS is one of the most widely applied technology platform used to analyse metabolite levels. This method facilitates the identification and robust quantification of metabolites [22-24]. However, this profiling technology is often applied to whole plants or organs. As a consequence such metabolite profiles have a low spatial resolution. The knowledge of the distribution of metabolites in specific tissues or specialized plant-cells is, however, indispensable to understand the bioactive role of these molecules. 
Recently, comprehensive metabolome profiling of mycorrhizal roots of barrel medic at different colonization stages was carried out by the combined application of GC-MS, HPLC and LC-MS [1]. Based on this information the combination of laser microdissection and micro-metabolomics profiling can be expected to enhance the insight into cellular metabolic processes during the symbiotic interactions with adequate spatial resolution. In this report, we address the adaptation of the plant host cells and the fungal organism to the symbiotic interaction with a specific focus on the differential accumulation of primary metabolites.

\section{Results and discussion}

\section{Metabolite profiling of distinct cell types of mycorrhizal} roots

In a fully developed AM symbiosis, different symbiotic structures are present in a root system. AM fungi form intracellular structures in inner cortical root cells named arbuscules, which are the site of nutrient transfer from fungus to the host plant. These cortical cells undergo a profound transcriptional reprogramming [13, 19, 25] leading to morphological and physiological changes including the development of a novel membrane type the periarbuscular membrane (PAM). Recent approaches using Laser Capture Microdissection of arbuscule containing cells revealed insights about transcriptome [19] and proteome changes [20] in these cells. Metabolome changes in mycorrhizal $M$. truncatularoots have previously been characterized at whole root level $[1,26]$. However, currently no datasets about the specific metabolite composition of colonized cells are available.

Here, we combinedthe LCM technique with a gas chromatography coupled to highly sensitive time-offlight mass spectrometry (GC-EI/TOF-MS) to investigate the metabolic changes in arbuscule-containing cells from mycorrhizal $M$. truncatula roots.

For this purpose we used a modified a protocol originally developed for metabolite measurements in vascular bundle cells of A. thaliana [15] (Fig. 1). These modifications were necessary, as the highly sensitive analytical method needed a reduction of the background caused by polymeric substances originating from the fixation medium. Root fragments were longitudinally sectioned and colonized as well as non-colonized root cells were microscopically identified, cut and collected.

A microscopic image of arbuscule-containing cells, which were collected for the analyses, is shown in Additional file 1: Figure S1.

In total, 13,638 arbuscule containing cells (arb) and 12,560 cortical cells (cor) were isolated and subjected to GC-EI/TOF-MS analysis. GC-MS measurements revealed a clear difference in the metabolite composition between both cell types (Fig. 2). This indicated that GCEI/TOF-MS-mediated analysis of primary metabolites is feasible in LMD-isolated cells and the applied method is sensitive enough to analyse limited root material.

Overall 56 annotated polar primary metabolites and 14 yet unidentified polar primary metabolites were detected in both cell populations (Additional file 2: Table S1, Additional file 3: Figure S2). The ion count ratio for each metabolite pointed to anaccumulation of distinct metabolites in arb cells (Fig. 2, Additional file 2: Table S1 and Additional file 3: Figure S2). Previously Schliemann et al. detected and quantified 81 polar compounds in roots colonized or not with Rhizophagus irregularis [1].

Furthermore 71 analytes were found by Laparre et al. to be mycorrhiza-associated [26]. In comparison to these studies it was not possible to increase the total number of detectable primary metabolites, but the application of our high-resolution method enabled the spatial information about mycorrhizal dependent accumulation of specific compounds.

LCM is a powerful tool to increase the spatiotemporal information of a given cell area or cell type $[27,28]$. In recent studies, this method was successfully coupled to metabolome studies of plant tissue using GC-MS [15]. A detailed overview about handling samples for plant metabolomics has been reported in various reviews [12, 27, 29, 30]. But so far, high-resolution methods to determine metabolite changes in cells which are directly associated with the symbiotic interface are missing. Thus, the application of micro-metabolomics enables the elucidation of cell type-specific changes taking place during the arbuscular mycorrhizal symbiosis.

Although the complex chemical impurities are still detectable as background in the analysed cell populations (Additional file 4: Figure S3a), the determination of ions derived from polar primary metabolites revealed clear differences in the accumulation of these compounds. As an example, sucrose and $\alpha$, $\alpha$ trehalose could be detected as accumulating compounds in colonized cells in comparison to non-colonized cells after subtracting the impurities of the non-sample control (Additional file 4: Figure S3a).

A GC-EI/TOF-MS-Chromatogram depicting the absolute total ion count (TIC) of detected compounds in arbuscule containing cells and cortical cells of noncolonized roots of Medicago is shown in Additional file 4: Figure S3b. The count of ions in arb and cor cells was conducted in relation to the non-sample control, which consist of tissue embedding material.

\section{Nutrient transfer at a cellular level}

Most analytes in arbuscule containing cells are related to the nitrogen metabolism All analyzed amino acids showed an accumulationin response to colonization (Additional file 3: Figure S2). Asparagine, aspartic acid as 


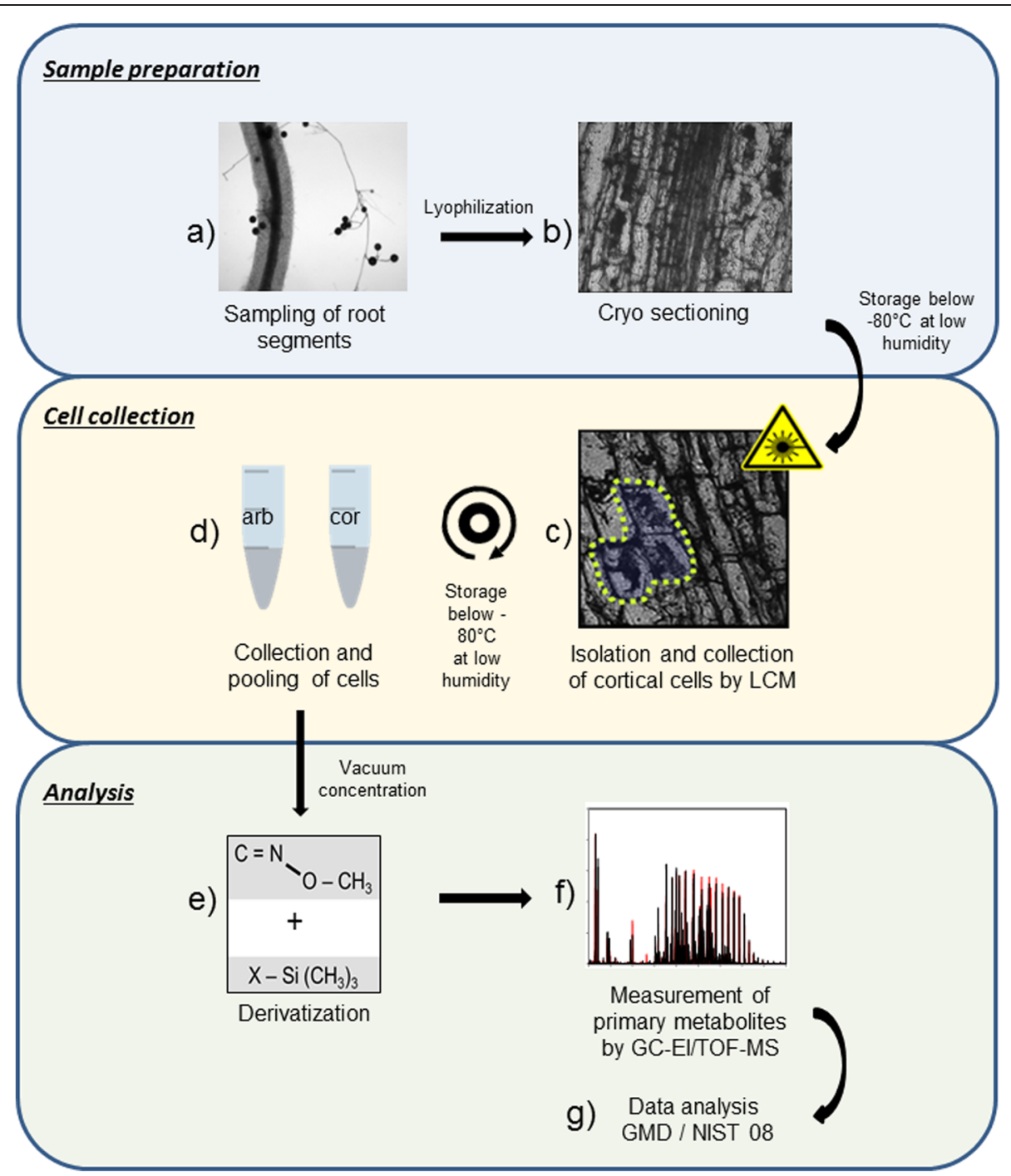

Fig. 1 Workflow illustration: LCM-mediated harvest of root cortex cells for metabolite profiling. Root fragments of mycorrhizal and non-mycorrhizal Medicago truncatula plants were lyophilized and sectioned with a cryostat (a and $\mathbf{b}$ ). In $35 \mu \mathrm{m}$ longitudinal sections, cortical cell populations were identified and isolated by laser microdissection (c and d). Approximately 13,000 cells for each cell type (arbuscule containing cells of mycorrhizal roots [arb] and cortical cells of non-colonized roots [cor]) were collected and subjected to derivatization (e). GC-EI/TOF-MS measurements facilitated the abundance of primary metabolites in the analysed samples (f). The corresponding compounds were identified through spectral matching against the National Institute of Standards and Technology library (NIST08) (g)

well as glutamic acid show the highest upregulation (Fig. 2). These findings are in a line with recent data showing the over accumulation of Glu, Asp and Asn for whole roots after colonization with $R$. irregularis [1]. In addition we could identify amino acids accumulating to a lower extend in arb cells. Glycine, homoserine, valine, leucine, serine, proline and threonine (Fig. 2). In summary, among the 56 identified primary metabolites in root cortex cells, 14 compounds could be classified as amino acids and all of them are upregulated in colonized root cells (Additional file 3: Figure S2).
Amino acids act as nitrogen donors, are related to stress and defense mechanisms and serve as a pool for the synthesis of other compounds. Additionally they can facilitate the nitrogen transport. Govindarajulu et al. [5] showed, that also high amounts of nitrogen are delivered to the plant during the AM symbiosis. Nitrogen is taken up from the soil by the fungal extraradical mycelium and translocated to the plant as arginine. A high proportion of the total root nitrogen originates from this symbiotic transfer [5]. Ammonium is released within the plant cells and can be assimilated to amino acids via the glutamine synthetase-glutamate synthase pathway (GS- 


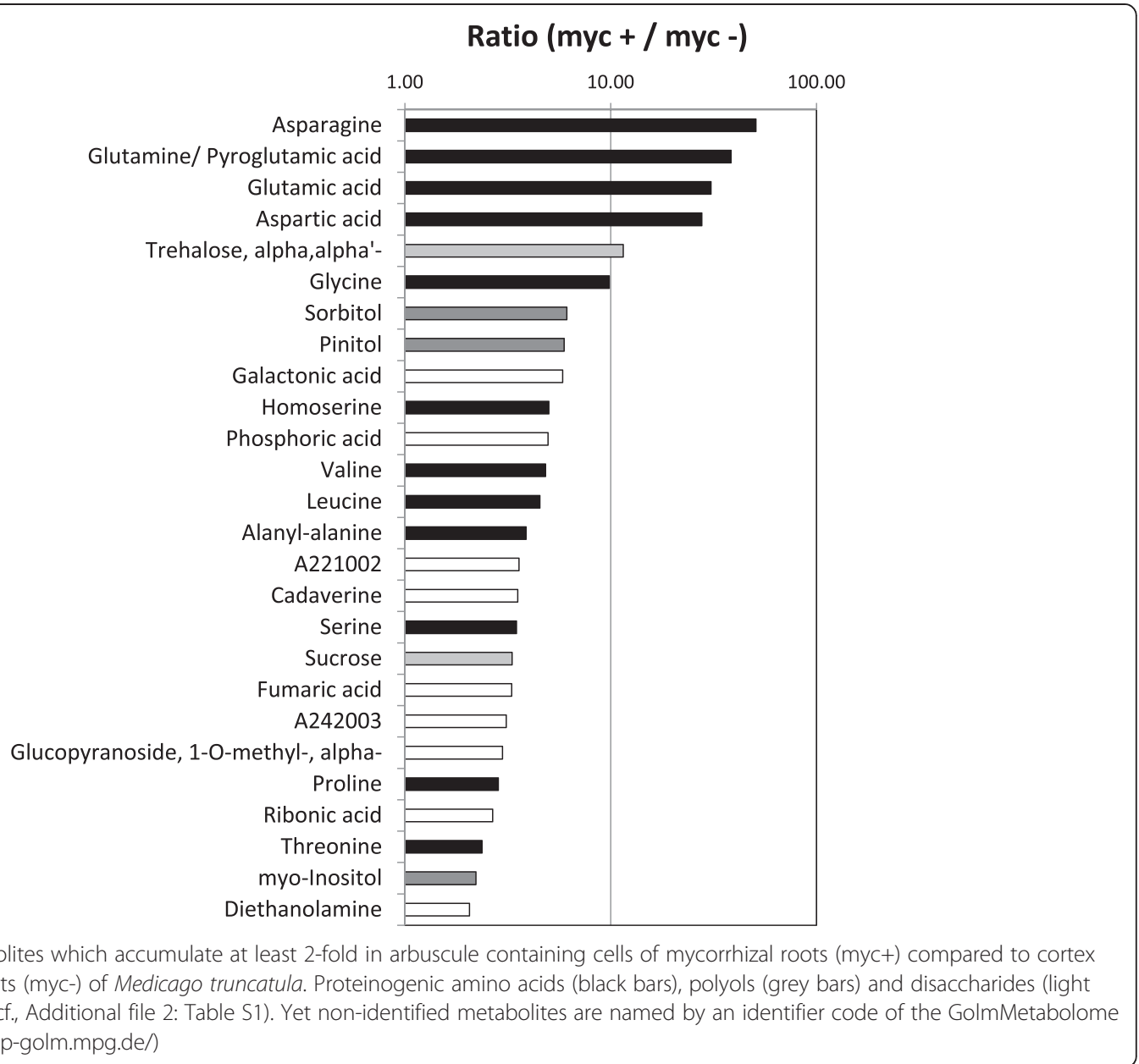

GOGAT). In our transcriptomic study [19] of arbuscule containing cells we observed a high expression level of a gene encoding a glutamine synthase (mtr.36015.1.s1_at). On the other hand genes encoding nitrate reductases (mtr.10604.1.s1_at, mtr.42446.1.s1_at) are down regulated which indicates a reduced nitrate metabolism. In previous studies two putative ammonium transporters were identified, of which one (medtr7g075790.2) is induced in non-colonized cells of mycorrhizal roots cells only, whereas the other (medtr7g140920.1) is strongly induced only in arb cells [19]. Our results point to an improved $\mathrm{NH}_{4}^{+}$availability in the plant cell during the AM symbiosis, which is directly channelled into the amino acid synthesis. Increased amounts of asparagine, aspartic acid and glutamic acid in arbuscule containing cells are obviously associated with the higher nitrogen availability. An elevated level of arginine was not observed indicating a rapid turnover in the intraradical mycelium.

An accumulation of intermediatesof the mitochondrial tricarboxylic acid cycle (TCA) such as fumarate and succinate could be detected, whereas the level of malate, an additional compound of the TCA cycle remained unchanged (Fig. 2, Additional file 3: Figure S2). The synthesis of some amino acids such as aspartic acid and glutamic acid utilizes TCA cycle intermediates. Further, an activation of fluxes through the TCA cycle was already shown amongst others with ${ }^{13} \mathrm{C}$ labelling experiments in extraradical mycelium [31] and in the intraradical mycelium [32].

Carbon allocation in colonized cortex cells The most striking differences in cell specific metabolite distribution were found for those metabolites associated with nutrient transfer between plant host and fungal partner. As expected, high levels of trehalose, presumably of fungal origin, were accumulating in arb cells (Fig. 2) as already described by [1]. Trehalose is a common carbohydrate in fungi, bacteria and insects. Genes encoding for enzymes of the trehalose biosynthesis pathway were found in higher plants too, but the amount of this disaccharide is very low [33].

Recently it was shown that trehalose can act as a sucrose analogue to interfere with carbohydrate allocation. In detail, trehalose can affect carbohydrate-mediated 
gene expression by two hypothetical mechanisms: as an analogue of sucrose or, after cleavage, by release of glucose, and thus play a role in metabolic fine-tuning and in plant development $[34,35]$. In transcriptomic studies we could already observe the high expression of sucrose regulated genes, such as sucrose synthase, specifically in arb cells [19]. These data are in line with proteomicdata analyses, were we found an accumulating sucrose synthase [20]. In our previous studies, genes directly related to the trehalose synthesis were not detected. But nevertheless, the cell specific accumulation of trehalose in arb cells might influence the metabolism in the colonized cells during the development of mycorrhizal structures by its role as signaling molecule.

We observed a strong increase of sucrose levels in arb cells. Sucrose represents the main form of carbohydrate transport in plants. In several studies, increased levels of specific sugars were observed in mycorrhizal roots [1, 36]. Saccharides either represent structural components, or serve as precursor molecules for the synthesis of a broad range of other metabolites in both, fungal and plant organisms. The fungal intraradical mycelium can take upglucose and, to a minor extent, fructose, butnot sucrose [37, 38]. M. truncatula mutants affected in sucrose metabolism are impaired in arbuscule development and maintenance [39]. Sucrose is cleaved by sucrose synthases, and / or invertases in the interfacial apoplast and the corresponding hexoses are taken up by the fungus. Additionally, sucrose mobilized in the cortical cells of mycorrhizal roots can serve as a carbon pool required for the synthesis of the periarbuscular membrane (PAM) in arb cells [20].

In contrast, we found only slight changes in the levels of hexoses (glucose and fructose) in arb cells when compared to cor cells. This might indicate a rapid uptake and metabolism of these hexoses by the fungus. The fast conversion of hexoses to the fungal storage compounds trehalose and glycogen was described recently [40].

The reduced amounts of maltose in colonized cortex cells (Fig. 3, Additional file 3: Figure S2) might indicate a rapid breakdown to glucose by maltases.

Previous findings suggested changes in the root carbon status during mycorrhization. In detail, mycorrhizal colonization of Lotus japonicus roots led to a decrease in starch concentration [41]. Probably starch degradation takes place in source organs or tissues whereat maltose is formed and further cleaved to sucrose. Sucrose is transported to the root cortex cells were it is directly used for carbon supply to the fungus. Afterwards it is cleaved to glucose as this is the form of carbohydrate that is preferentially taken up by the fungus, as shown in ${ }^{14} \mathrm{C}$ labeling experiments [42]. This explains the only slightly increased levels

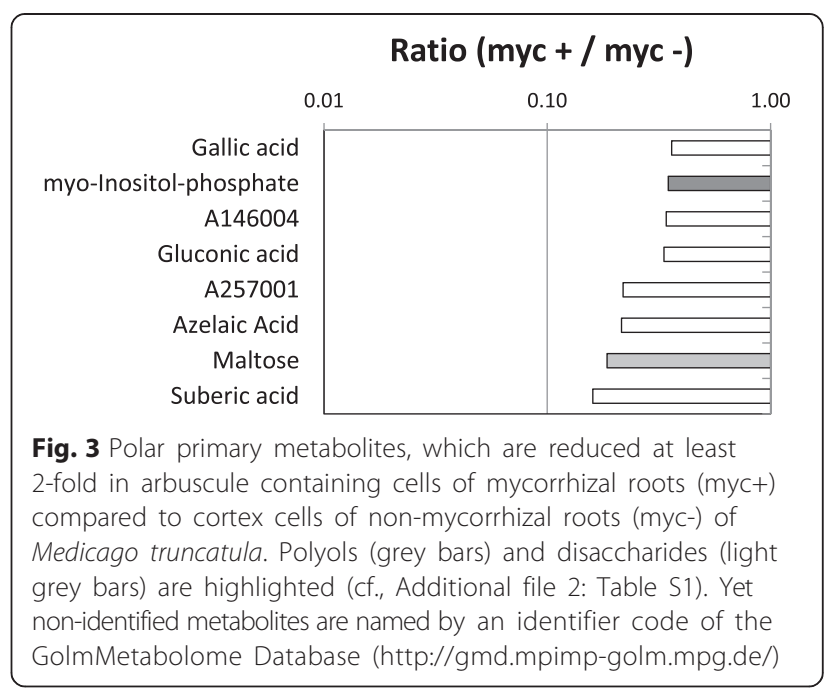

of glucose (Fig. 2), as the glucose is rapidly taken up and metabolized by the fungus.

Phosphate uptake in colonized cells The phosphate uptake by the plant plays a central role in the hostfungus interaction. The increased phosphate availability, mediated by the fungal uptake and transfer, is the main benefit for the host plant $[43,44]$. The phosphate content (Fig. 2, Additional file 3: Figure S2) is highly elevated in arb cells confirming the transfer of phosphate via the mycorrhizal pathway [45]. Specific plant phosphate transporters are expressed in arb cells [46-49], which mediate the uptake of phosphate from the periarbuscular space into the plant cell. This indicates that arbuscule-containing cells are the site of phosphate transfer between AM fungus and host plants. A strong increased transcript abundance of the phosphate transporter MtPt4 and the phosphate-responsive ubiquitinconjugating enzyme $\mathrm{PHO} 2$ was detected for arbuscule and the adjacent non-colonized cells, but only at a very low level in control cells of non-mycorrhizal roots [19]. These are examples how an improved phosphate level in the colonized and adjacent cells influences the transcription of phosphate responsive genes.

\section{Metabolite pattern indicates increased stress tolerance and reduced defense reactions}

In the present study, significant amounts of the polyamines cadavarine, diethanolamine and to a lower extend spermidine were detectedin response to the development of mycorrhizal structures in the root cortex (Fig. 2, Additional file 3: Figure S2). Putrescine was found in arbuscule containing cells of mycorrhizal roots, but not in non-colonized root cells (Additional file 3: Figure S2). Further components related to polyamine biosynthesis were not detectable in our samples. 
In general polyamines are involved in cell division and differentiation and play a beneficial role in the mycorrhizal symbiosis [50-52].

Another class of primary metabolites predominantly detected in colonized cortex cells is represented by the sugar alcohols sorbitol and pinitol. Polyols are alcohols containing multiple hydroxyl groups and their abundance often points to stress responses. As an example, pinitol accumulates during salt acclimation, but it was also reported to increase in mycorrhizal roots of Lotus japonicus $[1,4,53]$. Similarly, sorbitol was found to provide protection against salt stress in yeast [54] and is part of the fungal cell wall. Moreover, sorbitol is a direct product of the photosynthesis and functions as translocator of carbon skeletons and energy between sink and source organs in plants [55].

An addition, galactonic acid accumulates in arbusculecontaining cells, which can serve as a precursor for ascorbate biosynthesis. Several other organic acids, i.e. gallic acid and gluconic acid,were reduced in this cell type (Fig. 3, Additional file 3: Figure S2). Gallic acid, a soluble phenolic compound, can be found in a broad range of plant species and shows anti-fungal activity. Lattanzio et al. described the sensitivity of mycorrhizal fungi to phenolic compounds [56]. A reduction of this organic acid was detected in arbuscule containing cells indicating a repressed plant defense to accommodate the fungus. For the same reason, gluconic acid is reduced in colonized cells of mycorrhizal $M$. truncatula roots as it also function as an anti-fungal agent [57]. Gluconic acid can be produced by root-colonizing plant growthpromoting rhizobacteria (PGPR) and is a component of root exudates secreted to solubilizephosphate from the rhizosphere under phosphate limitation conditions [58]. Therefore, the improved phosphate status of a mycorrhizal plant leads to a reduction of this organic acid, too.

In the current study a reduced level of azelaic acid, a dicarboxylic acid, was determined in arb cells (Additional file 3: Figure S2). This defense compound confers resistance to pathogenic bacteria by priming the systemic plant immunity [59]. Although no antifungal activity was observed in vitro for azelaic acid [59] root cortex cells might decrease the amounts of azelaic acid to accommodate the mycorrhizal fungus.

\section{Conclusions}

A combination of cryosectioning and LCM for cell isolation, followed by GC-EI/TOF-MS as analytical tool, enabled us to determine changes in primary metabolite distribution as a result of the colonization of $M$. truncatula roots by the AM-fungus $R$. irregularis. These changes in metabolism strongly suggest a symbiosisdependent adaptation of the colonized cortical root cells to accommodate the fungal partner.
Furthermore, the here developed protocol for the analysis of M. truncatula roots is a reliable and valuable tool for further investigations, e.g., of the lipophilic and secondary metabolites in colonized mycorrhizal cells from Medicago roots.

\section{Methods}

\section{Plant material and growth conditions}

Medicago truncatula Gaertn. cv. Jemalong (A17) seeds were scarified in concentrated $\mathrm{H}_{2} \mathrm{SO}_{4}$ for $8 \mathrm{~min}$, rinsed 8-10 times with water and surface sterilized with $6 \%$ sodium hypochlorite for $10 \mathrm{~min}$. The seeds were distributed on wet filter paper in Petri dishes. Stratification was carried out at $4{ }^{\circ} \mathrm{C}$ overnight. The seeds were incubated for further 4 days at $25{ }^{\circ} \mathrm{C}$, in the dark. The seedlings were planted in to pots containing a mixture of clay, silica sand, vermiculite and inoculum with Rhizophagus irregularis $(30 \% v / v)$ as a substrate. Inoculum was obtained by pre culturing of Allium schoenoprasumwith Glomus intraradices. The plants were grown under controlled environmental conditions in a greenhouse for 21 days at $24{ }^{\circ} \mathrm{C}$ with a 16 -h-light / 8-h-dark cycle. Plants were fertilized with $0.5 \times$ Hoagland solution [60] containing $20 \mu \mathrm{M}$ phosphate, twice per week.

\section{Protocol for Laser Capture Microdissection (LCM)-mediated collection of cortical cells for metabolite profiling}

Scalpel dissected root fragments (1 cm long) of mycorrhizal (21 dpi) and non-mycorrhizal Medicago truncatula plants were snap-frozen in liquid $\mathrm{N}_{2}$ and thoroughly dried by $12 \mathrm{~h}$ lyophilisation (ALPHA 2-4, Christ, Osterode, Germany) to inhibit metabolite changes due to enzyme activity and the loss of solutes. To avoid excessive contaminations by embedding material (Tissue freezing medium, Electron Microscopy Sciences, Hatfield, USA), the lyophilized root pieces were arranged on the top of a frozen embedding material block and glued by a short touch of the embedding block with a finger. Longitudinal sections (30 $\mu \mathrm{m}$ thick) were cut by using a cryostat at $-22{ }^{\circ} \mathrm{C}$ (Leica CM 1950 Cryostat, Leica Microsystem, Wetzlar, Germany). Uncoated glass slides (Super frost, VWR, Darmstadt, Germany) were washed with ethanol (Merck, Darmstadt, Germany) and after drying with root sections assembled. The P.A.L.M. Laser Microbeam System (Bernried, Germany) was utilized for microdissection of cortical root cells. The following parameters were selected using P.A.L.M.Robosoftware 2003 (Microlaser Technologies, Bernried, Germany): auto-LPC focus, with energy of 95 and a speed of 100 (system specific units). The cutting and isolation was done under manual supervision with a low heat UV (337 nm nitrogen) laser at 40fold magnification.

All consumables (tips and reaction tubes) were washed twice with ethanol and dried. Isolated specimens were 
directly catapulted in a lid of $0.5 \mathrm{ml}$ reaction tubes with adhesive caps (Carl Zeiss Microimaging, Göttingen, Germany). Thirteen thousand six hundred thirty-eight arbuscule containing cells of mycorrhizal roots and 12,560 cortical cells of non-colonized roots were collected for subsequent metabolite analysis. The cell volume of each single dissected sample was estimated by the LCM software package by using the P.A.L.M. Robosoftware 1.2 (Microlaser Technologies, Bernied, Germany) and sum up to calculate the total cell volume.

\section{Metabolite extraction and profiling}

Polar primary metabolites of the cell type-specific populations obtained by laser capture microdissection from lyophilized Medicago truncatula roots were analyzed by gas chromatography-electron impact ionization/ time of flight-mass spectrometry (GC-EI/TOF-MS). Due to the high concentration factor required after extraction and because of the contact of the sample with embedding material and sampling tubes with adhesive caps, contaminations by respective laboratory chemicals were expected. To distinguish between contaminants and the endogenous metabolites of the collected single cell population's non-sample control experiments were performed with empty LCM-tubes. The tubes were either filled with $300 \mu \mathrm{l}$ ethanol or with a mixture of $300 \mu \mathrm{l}$ ethanol and $1 \mathrm{~mm}^{3}$ embedding material and processed in parallel with the regular samples. Cells isolated by laser capture microdissection were collected at the bottom of the tube by vigorously shaking in $300 \mu \mathrm{l}$ ethanol and centrifugation for $2 \mathrm{~min}$ at $20.000 \mathrm{~g}$. The samples were dried by vacuum centrifugation (Concentrator 5301, Eppendorf, Hamburg, Germany) without removing residual solid material of the cuttings and stored at $-80{ }^{\circ} \mathrm{C}$ for up to 3 months in the presence of silica balls. The dry pellet was dissolved in $3 \mu \mathrm{l}$ freshly prepared methoxamine hydrochloride dissolved at $40 \mathrm{mg} / \mathrm{mL}$ in pure pyridine and incubated at $30{ }^{\circ} \mathrm{C}$ for $90 \mathrm{~min}$, followed by derivatization with $9 \mu \mathrm{l}$ of a mixture consisting of $N$-methyl- $N$-(trimethylsilyl)-trifluoroacetamide (MSTFA) and a time standard $\left(\mathrm{C}_{10}, \mathrm{C}_{12}, \mathrm{C}_{15}, \mathrm{C}_{18}, \mathrm{C}_{19}, \mathrm{C}_{22}, \mathrm{C}_{28}, \mathrm{C}_{32}\right.$ and $\mathrm{C}_{36} \mathrm{n}$ alkane mixture) at $37{ }^{\circ} \mathrm{C}$ for $30 \mathrm{~min}$ [61]. Care was taken to avoid humidity throughout the process. The alkanes added to the samples were used to calculate retention time indices (RIs) [62].

The samples were analysed immediately after chemical derivatization by GC-EI/TOF-MS profiling using an Agilent $6890 \mathrm{~N}$ gas chromatograph (Agilent Technologies, Böblingen, Germany) with splitless injection onto a FactorFour VF-5 ms capillary column, $30 \mathrm{~m}$ length, $0.25 \mathrm{~mm}$ inner diameter, $0.25 \mu \mathrm{m}$ film thickness (Varian-Agilent Technologies), which was connected to a Pegasus III time of flight mass spectrometer (LECO
Instrumente $\mathrm{GmbH}$, Mönchengladbach, Germany) as described by [61, 63]. Two technical replicates of each sample were conducted.

\section{Data analysis}

GC-EI/TOF-MS chromatograms were baseline corrected and exported in NetCDF file format using ChromaTOFsoftware (Leco, St. Joseph, USA). Primary metabolites were identified manually supervised by differential analysis compared to the non-sample controls and subsequent spectral and retention index matching against the reference collections of the Golm Metabolome database (http://gmd.mpimp-golm.mpg.de/) [64-66] and of the National Institute of Standards and Technology (NIST 08; http://www.nist.gov/srd/nist1a.cfm). Guidelines for manually supervised metabolite identification were the presence of at least 3 specific mass fragments per compound and a retention index deviation $<1.0 \%$ [62].

Peak heights of observed mass features were extracted from the NETCDF files and aligned according to retention index and processed into a standardized numerical data matrix using the TagFinder software [67]. Background subtraction of peak heights was performed, if required, using the average peak height of non-sample controls. Normalized responses were calculated, dividing by total estimated cell volume of the pooled microdissected samples (using LCM software package P.A.L.M. Robosoftware 1.2, Microlaser Technologies, Bernried, Germany) and dividing by peak height of the internal standard, docosane. Docosane was absent from the non-sample controls. The normalized response of a metabolite in the arbuscular cell preparation was divided by the normalized response of the metabolite in the cortex cells.

\section{Additional files} Additional file 1: Figure S1. Example of a colonized area used for
the sample collection via LCM. Longitudinal cryosections ( $35 \mathrm{\mu m}$ ) of
roots 21 day post infection with Rhizophagus irregularis or control
non-mycorrhizal roots were used for cell sampling. As an example,
arbuscule-containing cells (arb) collected for this study are highlighted with
yellow dashed lines. (PPT 849 kb)
Additional file 2: Table S1. Summary of polar primary metabolites
identified in root cortical cells of mycorrhizal and non-mycorrhizal roots of
M. truncatula. Polar metabolites were analysed by GC-El/TOF-MS based on
metabolic profiling of methoxyaminated and trimethylsilylated metabolites.
Data are expressed as means of two technical replicates. (XLS 57 kb)
Additional file 3: Figure S2. Polar primary metabolites which were
detectable in arbuscule containing cells of mycorrhizal roots (myc+) and in
cortex cells of non-mycorrhizal roots (myc-) of Medicago truncatula or in
either of the cell types. Metabolites are sorted within class according fold
change. Yet non-identified metabolites are omitted (cf., Supplemental Table
S1). Mean centered normalized responses and the respective response ratios
are shown. (PPT 173 kb) 
Additional file 4: Figure S3. GC-El/TOF-MS-Chromatograms of a primary metabolite fraction that was extracted from cell populations of $\sim 13,000$ arbuscule containing root cells (red) after laser capture dissection compared to an extract from an approximately equal number non-colonized cortical cells of Medicago truncatula (black). (A) Selected ion monitoring using specific and selected mass fragments allows the highly selective relative quantification of metabolites in highly complex preparations that may contain unavoidable chemical contaminations. The chosen mass fragment, $\mathrm{m} / \mathrm{z}=361$, allows the specific analysis of sucrose and a,a-trehalose at retention times that were determined by pure authenticated reference compounds. The insert shows the $a, a$-trehalose peak compared to a non-sample control (grey). The arrow indicates one of the impurities that need to be eliminated from further analysis by background subtraction. (B) Total ion chromatogram (TIC) of the same samples exemplifies the complex chemical impurities, which result from the embedding material that is required for the laser capture dissection process. Note, one mycorrhization-responsive compound, i.e., asparagine (red arrow), was already directly detectable by differential display analysis of the TICS. (PPT $1315 \mathrm{~kb}$ )

\section{Abbreviations}

AM symbiosis: Arbuscular mycorrhizal symbiosis; arb: Arbuscule containing cells of mycorrhizal roots; cor: Cortical cells of non-mycorrhizal roots; GC-El/ TOF-MS: Gas chromatography-mass spectrometry, HPLC, High performance liquid chromatography; LCM: Laser Capture Microdissection; LC-MS: Liquid chromatography-mass spectrometry; myc+: Mycorrhizal roots; myc-: Nonmycorrhizal roots; TIC: Total ion chromatogram.

\section{Competing interests}

The authors declare that they have no competing interests.

\section{Authors' contributions}

$N G, S B$ and AE performed biological experiments. FK, NG and JK designed and initiated the research. All authors analyzed the data. NG, JK, AE, SB and FK wrote and approved the manuscript.

\section{Acknowledgments}

This work was funded by the Max Planck Society, Germany. S.B. was supported by the German Research Foundation (SPP Plant Microbe Interaction).

We would like to thank Ines Fehrle from the Max Planck Institute of Molecular Plant Physiology for technical assistance.

\section{Received: 24 February 2015 Accepted: 4 September 2015} Published online: 30 September 2015

\section{References}

1. Schliemann W, Ammer C, Strack D. Metabolite profiling of mycorrhizal roots of Medicago truncatula. Phytochemistry. 2008;69(1):112-46.

2. Lohse S, Schliemann W, Ammer C, Kopka J, Strack D, Fester T. Organization and metabolism of plastids and mitochondria in arbuscular mycorrhizal roots of Medicago truncatula. Plant Physiol. 2005;139(1):329-40.

3. Schaarschmidt S, Kopka J, Ludwig-Muller J, Hause B. Regulation of arbuscular mycorrhization by apoplastic invertases: enhanced invertase activity in the leaf apoplast affects the symbiotic interaction. Plant J. 2007;51(3):390-405.

4. Fester T, Fetzer I, Buchert S, Lucas R, Rillig MC, Hartig C. Towards a systemic metabolic signature of the arbuscular mycorrhizal interaction. Oecologia. 2011;167(4):913-24.

5. Govindarajulu M, Pfeffer PE, Jin HR, Abubaker J, Douds DD, Allen JW, et al. Nitrogen transfer in the arbuscular mycorrhizal symbiosis. Nature. 2005:435(7043):819-23.

6. Gachomo E, Allen JW, Pfeffer PE, Govindarajulu M, Douds DD, Jin HR, et al. Germinating spores of Glomus intraradices can use internal and exogenous nitrogen sources for de novo biosynthesis of amino acids. New Phytol. 2009;184(2):399-411.
7. Jin H, Pfeffer PE, Douds DD, Piotrowski E, Lammers PJ, Shachar-Hill Y. The uptake, metabolism, transport and transfer of nitrogen in an arbuscular mycorrhizal symbiosis. New Phytol. 2005;168(3):687-96.

8. Jin HR. Arginine bi-directional translocation and breakdown into ornithine along the arbuscular mycorrhizal mycelium. Sci China Ser C-Life Sci. 2009;52(4):381-9.

9. Bago B, Pfeffer PE, Shachar-Hill Y. Carbon metabolism and transport in arbuscular mycorrhizas. Plant Physiol. 2000;124(3):949-57.

10. Douds DD, Pfeffer PE, Shachar-Hill Y. Application of in vitro methods to study carbon uptake and transport by AM fungi. Plant Soil. 2000;226(2):255-61.

11. Harrison MJ. Signaling in the arbuscular mycorrhizal symbiosis. Annu Rev Microbiol. 2005;59:19-42.

12. Moco S, Schneider B, Vervoort J. Plant Micrometabolomics: The analysis of endogenous metabolites present in a plant cell or tissue. J Proteome Res. 2009;8(4):1694-703.

13. Gomez SK, Javot H, Deewatthanawong P, Torres-Jerez I, Tang YH, Blancaflor EB, et al. Medicago truncatula and Glomus intraradices gene expression in cortical cells harboring arbuscules in the arbuscular mycorrhizal symbiosis. Bmc Plant Biology. 2009;9:19.

14. Schad M, Lipton MS, Giavalisco P, Smith RD, Kehr J. Evaluation of twodimensional electrophoresis and liquid chromatography-tandem mass spectrometry for tissue-specific protein profiling of laser-microdissected plant samples. Electrophoresis. 2005;26(14):2729-38.

15. Schad M, Mungur R, Fiehn O, Kehr J. Metabolic profiling of laser microdissected vascular bundles of Arabidopsis thaliana. Plant Methods. 2005;1(1):2.

16. Schneider B, Holscher D. Laser microdissection and cryogenic nuclear magnetic resonance spectroscopy: an alliance for cell type-specific metabolite profiling. Planta. 2007;225(3):763-70.

17. Klink VP, Hosseini P, Matsye P, Alkharouf NW, Matthews BF. A gene expression analysis of syncytia laser microdissected from the roots of the Glycine max (soybean) genotype PI 548402 (Peking) undergoing a resistant reaction after infection by Heterodera glycines (soybean cyst nematode). Plant Mol Biol. 2009;71(6):525-67.

18. Nelson T, Tausta SL, Gandotra N, Liu T. Laser microdissection of plant tissue: what you see is what you get. Annu Rev Plant Biol. 2006;57:181-201.

19. Gaude N, Bortfeld S, Duensing N, Lohse M, Krajinski F. Arbusculecontaining and non-colonized cortical cells of mycorrhizal roots undergo extensive and specific reprogramming during arbuscular mycorrhizal development. Plant J. 2012;69(3):510-28.

20. Gaude N, Schulze WX, Franken P, Krajinski F. Cell type-specific protein and transcription profiles implicate periarbuscular membrane synthesis as an important carbon sink in the mycorrhizal symbiosis. Plant Signal Behav. 2012;7(4):461-4.

21. Hogekamp C, Kuster H. A roadmap of cell-type specific gene expression during sequential stages of the arbuscular mycorrhiza symbiosis. BMC Genomics. 2013;14(1):306

22. Fiehn O, Kopka J, Dormann P, Altmann T, Trethewey RN, Willmitzer L. Metabolite profiling for plant functional genomics. Nat Biotechnol. 2000;18(11):1157-61.

23. Lisec J, Schauer N, Kopka J, Willmitzer L, Fernie AR. Gas chromatography mass spectrometry-based metabolite profiling in plants. Nat Protoc. 2006;1(1):387-96.

24. Kopka J. Current challenges and developments in GC-MS based metabolite profiling technology. J Biotechnol. 2006;124(1):312-22.

25. Hogekamp C, Arndt D, Pereira PA, Becker JD, Hohnjec N, Küster H. Laser Microdissection unravels cell-type-specific transcription in arbuscular mycorrhizal roots, including CAAT-Box transcription factor gene expression correlating with fungal contact and spread. Plant Physiol. 2011;157(4):2023-43.

26. Laparre J, Malbreil M, Letisse F, Portais JC, Roux C, Bécard G, et al. Combining metabolomics and gene expression analysis reveals that Propionyl- and ButyrylCarnitines are involved in late stages of arbuscular mycorrhizal symbiosis. Mol Plant. 2014;7(3):554-66.

27. Fang J, Schneider B. Laser Microdissection: a sample preparation technique for plant micrometabolic profiling. Phytochem Anal. 2013:n/a-n/a.

28. Rogers ED, Jackson T, Moussaieff A, Aharoni A, Benfey PN. Cell typespecific transcriptional profiling: implications for metabolite profiling. Plant J. 2012;70(1):5-17. 
29. Kim HK, Verpoorte R. Sample preparation for plant metabolomics. Phytochem Anal. 2010;21(1):4-13.

30. Hoelscher D, Schneider B. Application of laser-assisted microdissection for tissue and cell-specific analysis of RNA, proteins, and metabolites. Prog Bot. 2008;69:141-67.

31. Lammers PJ, Jun J, Abubaker J, Arreola R, Gopalan A, Bago B, et al. The glyoxylate cycle in an arbuscular mycorrhizal fungus. Carbon flux and gene expression. Plant Physiol. 2001;127(3):1287-98.

32. Saito M. Enzyme-activities of the internal hyphae and germinated spores of an arbuscular mycorrhizal fungus, Gigaspora margarita. Becker-and-Hall. New Phytol. 1995;129(3):425-31.

33. Ramon M, De Smet I, Vandesteene L, Naudts M, Leyman B, Van Dijck P, et al. Extensive expression regulation and lack of heterologous enzymatic activity of the Class II trehalose metabolism proteins from Arabidopsis thaliana. Plant Cell Environ. 2009;32(8):1015-32.

34. Garcia AB, De Almeida EJ, lyer S, Gerats T, Van Montagu M, Caplan AB. Effects of osmoprotectants upon $\mathrm{NaCl}$ stress in rice. Plant Physiol. 1997;115(1):159-69.

35. Müller J, Wiemken A, Aeschbacher R. Trehalose metabolism in sugar sensing and plant development. Plant Sci. 1999;147(1):37-47.

36. Boldt K, Pörs Y, Haupt B, Bitterlich M, Kühn C, Grimm B, et al. Photochemical processes, carbon assimilation and RNA accumulation of sucrose transporter genes in tomato arbuscular mycorrhiza. J Plant Physiol. 2011;168(11):1256-63.

37. Bago B, Pfeffer PE, Abubaker J, Jun J, Allen JW, Brouillette J, et al. Carbon export from arbuscular mycorrhizal roots involves the translocation of carbohydrate as well as lipid. Plant Physiol. 2003;131(3):1496-507.

38. Pfeffer PE, Douds DD, Becard G, Shachar-Hill Y. Carbon uptake and the metabolism and transport of lipids in an arbuscular mycorrhiza. Plant Physiol. 1999;120(2):587-98.

39. Baier MC, Keck M, Godde V, Niehaus K, Küster H, Hohnjec N. Knockdown of the symbiotic sucrose synthase MtSucS1 affects arbuscule maturation and maintenance in mycorrhizal roots of Medicago truncatula. Plant Physiol. 2010;152(2):1000-14.

40. Shacharhill $Y$, Pfeffer PE, Douds D, Osman SF, Doner LW, Ratcliffe RG. Partitioning of carbohydrate-metabolism in Vesicular-Arbuscular Mycorrhizal leek revealed by NMR-spectroscopy. Plant Physiol. 1995;108(2):22-2.

41. Gutjahr C, Novero M, Guether M, Montanari O, Udvardi M, Bonfante P. Presymbiotic factors released by the arbuscular mycorrhizal fungus Gigaspora margarita induce starch accumulation in Lotus japonicus roots. New Phytol. 2009;183(1):53-61.

42. Solaiman MDZ, Saito M. Use of sugars by intraradical hyphae of arbuscular mycorrhizal fungi revealed by radiorespirometry. New Phytol. 1997;136(3):533-8.

43. Bucher M. Functional biology of plant phosphate uptake at root and mycorrhiza interfaces. New Phytol. 2007;173(1):11-26.

44. Javot H, Pumplin N, Harrison MJ. Phosphate in the arbuscular mycorrhizal symbiosis: transport properties and regulatory roles. Plant Cell Environ. 2007;30(3):310-22.

45. Glassop D, Smith S, Smith F. Cereal phosphate transporters associated with the mycorrhizal pathway of phosphate uptake into roots. Planta. 2005;222(4):688-98.

46. Harrison MJ, Dewbre GR, Liu JY. A phosphate transporter from Medicago truncatula involved in the acquisiton of phosphate released by arbuscular mycorrhizal fungi. Plant Cell. 2002;14(10):2413-29.

47. Balestrini R, Gomez-Ariza J, Lanfranco L, Bonfante P. Laser microdissection reveals that transcripts for five plant and one fungal phosphate transporter genes are contemporaneously present in arbusculated cells. Mol Plant Microbe Interact. 2007;20(9):1055-62.

48. Rausch C, Daram P, Brunner S, Jansa J, Laloi M, Leggewie G, et al. A phosphate transporter expressed in arbuscule-containing cells in potato. Nature. 2001;414(6862):462-70.

49. Paszkowski U, Kroken S, Roux C, Briggs SP. Rice phosphate transporters include an evolutionarily divergent gene specifically activated in arbuscular mycorrhizal symbiosis. Proc Natl Acad Sci U S A. 2002;99(20):13324-9.

50. Elghachtouli N, Paynot M, Morandi D, Martintanguy J, Gianinazzi S. The effect of polyamines on endomycorrhizal infection of wild-type Pisum sativum, CV Frisson (Nod(+)Myc(+)) and 2 Mutants (Nod(-)Myc(+) and Nod(-)Myc(-)). Mycorrhiza. 1995;5(3):189-92.
51. Kytoviita MM, Sarjala T. Effects of defoliation and symbiosis on polyamine levels in pine and birch. Mycorrhiza. 1997;7(2):107-11.

52. Zarb J, Walters DR. The formation of cadaverine, aminopropylcadaverine and $\mathrm{N}, \mathrm{N}$ bis (3-aminopropyl) cadaverine in mycorrhizal and phytopathogenic fungi. Lett Appl Microbiol. 1994;19(4):277-80.

53. Sanchez DH, Lippold F, Redestig H, Hannah MA, Erban A, Kramer U, et al. Integrative functional genomics of salt acclimatization in the model legume Lotus japonicus. Plant J. 2008:53(6):973-87.

54. Bo S, Stefan H, Jensen RG, Bohnert HJ. Roles of sugar alcohols in osmotic stress adaptation. Replacement of glycerol by mannitol and sorbitol in yeast. Plant Physiol. 1999;121:45-52.

55. Noiraud N, Maurousset L, Lemoine R. Transport of polyols in higher plants. Plant Physiol Biochem. 2001;39(9):717-28.

56. Lattanzio V, Cardinali A. Role of phenolics in the resistance mechanisms of plants against fungal pathogens and insects. In: Filippo Imperato, editor. Research Signpost Phytochemistry: Advances in research. 2006. p. 23-67.

57. Kaur R, Macleod J, Foley W, Nayudu M. Gluconic acid: an antifungal agent produced by Pseudomonas species in biological control of take-all. Phytochemistry. 2006;67(6):595-604

58. Gaur AC, Ostwal KP. Influence of phosphate dissolving bacilli on yield and phosphate uptake of wheat crop. Indian J Exp Biol. 1972;10(5):393-4

59. Jung HW, Tschaplinski TJ, Wang L, Glazebrook J, Greenberg JT. Priming in systemic plant immunity. Science. 2009;324(5923):89-91.

60. Hoagland DR, Martin JC. Availability of potassium to crops in relation to replaceable and nonreplaceable potassium and to effects of cropping and organic matter. Soil Sci Soc Am Proc. 1950;15:272-8.

61. Erban A, Schauer N, Fernie AR, Kopka J. Nonsupervised construction and application of mass spectral and retention time index libraries from time-offlight gas chromatography-mass spectrometry metabolite profiles. Methods Mol Biol. 2007;358:19-38.

62. Strehmel N, Hummel J, Erban A, Strassburg K, Kopka J. Retention index thresholds for compound matching in GC-MS metabolite profiling. J Chromatogr B Analyt Technol Biomed Life Sci. 2008;871(2):182-90.

63. Allwood JW, Erban A, de Koning S, Dunn WB, Luedemann A, Lommen A, et al. Inter-laboratory reproducibility of fast gas chromatography-electron impact-time of flight mass spectrometry (GC-El-TOF/MS) based plant metabolomics. Metabolomics. 2009;5(4):479-96.

64. Kopka J, Schauer N, Krueger S, Birkemeyer C, Usadel B, Bergmuller E, et al. GMD@CSB.DB: the Golm Metabolome Database. Bioinformatics. 2005;21(8):1635-8.

65. Schauer N, Steinhauser D, Strelkov S, Schomburg D, Allison G, Moritz T, et al. GC-MS libraries for the rapid identification of metabolites in complex biological samples. Febs Letters. 2005;579(6):1332-7.

66. Hummel J, Strehmel N, Selbig J, Walther D, Kopka J. Decision tree supported substructure prediction of metabolites from GC-MS profiles. Metabolomics. 2010;6(2):322-33.

67. Luedemann A, Strassburg K, Erban A, Kopka J. TagFinder for the quantitative analysis of gas chromatography - mass spectrometry (GC-MS)-based metabolite profiling experiments. Bioinformatics. 2008;24(5):732-7.

\section{Submit your next manuscript to BioMed Central and take full advantage of:}

- Convenient online submission

- Thorough peer review

- No space constraints or color figure charges

- Immediate publication on acceptance

- Inclusion in PubMed, CAS, Scopus and Google Scholar

- Research which is freely available for redistribution 